\title{
Kompresi Citra Berwarna Menggunakan Transformasi Wavelet
}

\author{
Suma'inna, Dipo Alam \\ Program Studi Matematika Fakultas Sains dan Teknologi \\ Universitas Islam Negeri Syarif Hidayatulah Jakarta \\ e-mail : suma.inna@uinjkt.ac.id
}

\begin{abstract}
ABSTRAK
Kompresi citra merupakan proses mereduksi ukuran citra untuk menghasilkan representasi digital yang padat atau mampat, namun tetap dapat mewakili kualitas informasi yang terkandung pada citra tersebut. Pada dasarnya citra berwana adalah penggabungan dari 3 buah matriks piksel red, green dan blue disingkat RGB. Pada makalah ini, proses kompresi citra dilakukan dengan menggunakan dua metode wavelet yang terkenal, yaitu wavelet Haar dan Daubechies (Db2). Kedua metode itu dibandingkan untuk memperoleh informasi wavelet manakah yang optimum dalam kompresi citra. Proses kompresi pada citra dilakukan pada 1 level dan 2 level. Penelitian ini menggunakan citra true colour berformat jpg. Dari hasil yang didapat, wavelet Daubechies Db2 level 2 memberikan kompresi yang optimum berdasarkan nilai RMSE, PNSR dan rasion kompresinya.
\end{abstract}

Kata kunci: Kompresi Citra, wavelet Haar, wavelet Daubchies (Db2)

\section{ABSTRACT}

Image compression process is a process to reduce the size of the image and still able to represent the quality of the contained information in the image. Basically, color image is the combination of 3 pixel matrices red, green and blue abbreviated as RGB. In this paper, the image compression process was done using two well-known wavelet methods, the Haar and Daubechies wavelet (Db2). The methods were performed at level 1 and level 2 and were compared to obtain the information of which wavelet gave the optimum compression. This study used a true color image on jpg format. According to the results, Daubechies wavelet Db2 methods on level 2 provided the optimum compression based on the RMSE, PNSR and compression ratio values.

Keywords: Image compression, Haar wavelet, Daubechies wavelet (Db2)

\section{Pendahuluan}

Kompresi adalah sebuah metode yang bertujuan untuk mengecilkan ukuran file citra. Kompresi citra merupakan metode untuk memilih sinyal dalam citra digital berdasarkan frekuensi yang berbeda. Ada banyak metode untuk kompresi citra seperti kompresi menggunakan transformasi Fourier, metode pohon biner Huffman dan sebagainya. Pada makalah ini penulis menggunakan transformasi wavelet.

Wavelet merupakan sebuah metode pengolahan data yang memilih sinyal berdasarkan frekuensi yang berbeda. Transformasi wavelet dapat menangkap informasi suatu sinyal dan dapat memberikan informasi dimana frekuensi itu terjadi. Dewasa ini aplikasi dari wavelet semakin berkembang dalam berbagai macam bidang seperti pendeteksian kelainan jantung [7], deteksi gempa [8], dan penyelesaian persamaan differensial [1].

Ada dua tahapan proses transformasi pada pembahasan ini, yaitu Discrete Wavelet Transform (DWT) dan InverseDiscrete Wavelet Transform (IDWT). Tahapan DWT memungkinkan untuk memisahkan sinyal komponen citra berfrekuensi tinggi dan rendah, sehingga komponen citra berfrekuensi tinggi dapat dikurangi frekuansinya melalui proses kuantisasi. Proses kuantisasi bertujuan untuk mengurangi size citra. Tahapan IDWT merupakan kebalikan dari DWT, tahapan ini bertujuan untuk mengembalikan komponen-komponen citra hasil DWT kembali ke posisi awal sebelum citra diproses pada tahapan DWT.

Tahapan DWT dan IDWT juga dapat dilakukan terhadap citra yang telah terkompresi. Sehingga perpaduan tahapan DWT, IDWT dan dekuantisasi memungkinkan untuk mengembalikan citra hasil 
kompresi ke bentuk citra sebelum proses kompresi. Proses dekuantisasi dan IDWT adalah proses untuk mengembalikan intensitas citra hasil kuantisasi ke bentuk aslinya.

Pada [9] telah dilakukan kompresi citra hitam putih (grayscale). Pada [5], citra awal tetap merupakan citra berwarna, tetap dilakukan grayscaling baru dilakukan kompresi dengan menggunakan transformasi wavelet sementara pada makalah ini dilakukan kompresi pada citra berwarna tanpa dilakukan grayscaling. Pada penelitian tersebut diperoleh bahwa nilai PSNR citra kompresi dengan Db2 lebih besar dibanding wavelet Haar dan rasio kompresi citra dengan wavelet Haar lebih tinggi dibanding Db2. ada makalah ini dilakukan kompresi pada citra berwarna

\section{Metode Penelitian}

\subsection{Transformasi Wavelet}

Transformasi wavelet memberikan representasi frekeunsi waktu dari sinyal. Awalnya transformasi wavelet digunakan untuk menganalisis sinyal non-stasioner menggunakan analisis multi resolusi. Secara umum teknik analisis multi resolusi digunakan untuk menganalisis frekuensi yang berbeda menggunakan resolusi yang berbeda [6]. Analisis multiresolusi berisi keluarga subruang tertutup $\left\{V_{m}, m \in Z\right\}$ dari $L^{2}(R)$ yang memenuhi [4]:

1. $V_{m} \subset V_{m+1}$, untuk setiap $m \in Z$

2. $f(x) \in V_{m}$ jika dan hanya jika $f(2 x) \in V_{m+1}$.

3. $\bigcap_{m \in Z} V_{m}=\{0\}$

4. $U_{m \in Z} V_{m}=L^{2}(R)$

Terdapat fungsi skala $\phi(x)$ sedemikian sehingga $\left\{\phi_{0, n}=\phi(x-n), n \in Z\right\}$ merupakan basis ortonormal untuk $V_{0}$.

\subsection{Wavelet Haar}

Definisi Fungsi Skala wavelet Haar (Father Wavelet) adalah [3]:

$$
\varnothing(x)=\left\{\begin{array}{l}
1, x \in[0,1] \\
0, \text { untuk } x \text { yang lain }
\end{array}\right.
$$

Misal $V_{m}$ adalah ruang fungsi di $L^{2}(R)$ yang konstan pada interval $\left[2^{-m} n, 2^{-m}(n+1)\right], m, n \in Z$, maka $\left\{V_{m}: m \in Z\right\}$ adalah sebuah analisis multiresolusi yang bersesuaian dengan wavelet Haar. Wavelet Haar memenuhi persamaan dilasi

dimana

$$
\phi(x)=\sum_{n=-\infty}^{\infty} h(n) \phi_{1, n}(x)
$$

$$
h_{n}=\sqrt{2} \int_{-\infty}^{\infty} \phi(x) \phi(2 x-n) d x .
$$

Dengan demikian diperoleh $h_{0}=h_{1}=\frac{1}{\sqrt{2}}$ dan $h_{n}=0, n \neq 0,1$. Untuk wavelet Haar atau dikenal juga Daubechies 1 (db1) dengan koefisien $h_{0}=h_{1}=\frac{1}{\sqrt{2}}$ merupakan lowpass filter [2].

\subsection{Wavelet Daubechies}

Wavelet Daubechies merupakan pengembangan dari wavelet Haar. Daubechies 1 (db1) dengan panjang filter 2 merupakan wavelet Haar. Daubechies 2 disingkat (Db2) adalah wavelet Daubechies dengan banyak filter 4 dengan koefisien filter (lihat [5]]: $h_{0}=\frac{1+\sqrt{3}}{4 \sqrt{2}}, h_{1}=\frac{3+\sqrt{3}}{4 \sqrt{2}}, h_{2}=\frac{3-\sqrt{3}}{4 \sqrt{2}}, h_{3}=\frac{1-\sqrt{3}}{4 \sqrt{2}}$.

Hubungan antara lowpass filter $h_{n}$ dan highpass filter $g_{n}$ didefinisikan sebagai berikut [5]:

$$
g_{n}=-1^{n} h_{k-n-1}
$$


Dengan demikian dapat diperoleh bahwa, $g_{0}=h_{3}, g_{1}=-h_{2}, g_{2}=h_{1}, g_{3}=-h_{0}$, dimana untuk kasus transformasi Daubechies (Db2), sedangkan untuk transformasi Haar diperoleh $g_{0}=h_{1}, g_{1}=$ $-h_{0}$ dank menyatakan banyaknya koefisien filter dari $h_{n}$.

\subsection{Citra RGB (true color)}

Citra RGB dideskripsikan oleh kombinasi warna merah (Red), hijau (Green) dan biru (Blue). Masing-masing komponen mempunyai range antara 0-255, maka setiap warna dasar menggunakan penyimpanan 8 bit $=1$ byte, yang berarti setiap warna mempunyai gradasi sebanyak 256 warna. Total range yang digunakan untuk citra RGB adalah 256 pangkat 3 atau 16.777.216 kemungkinan warna. Range tersebut merupakan banyaknya gradasi warna yang terdapat pada citra yang membuat citra penuh warna sehingga citra RGB disebut true color.

Citra RGB juga disebut sebagai citra 24-bit colorimage karena sebuah citra RGB terdiri dari tumpukan 3 matriks yang mewakili merah, hijau dan biru dimana masing-masing matriks memiliki nilai 8-bit color image. Dengan perkataan lain setiap piksel memiliki 3 nilai. Untuk lebih jelasnya dapat dilihat Gambar berikut ini.

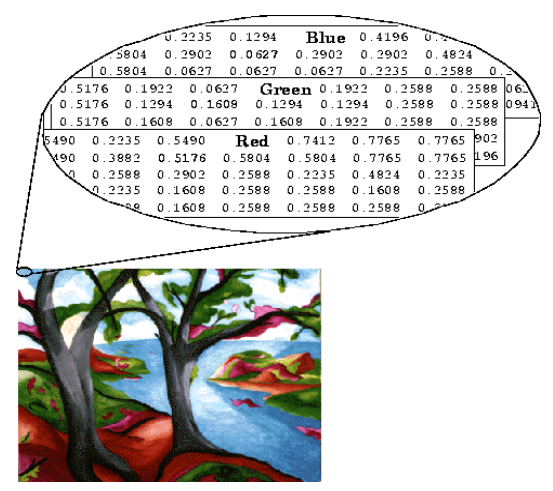

Gambar 1. Ilustrasi citra true color [2]

\subsection{Discrete Wavelet Transform (DWT) dan Invers Discrete Wavelet Transform(IDWT)}

DWT adalah proses dekomposisi citra yang dimulai dengan melakukan dekomposisi baris data citra, kemudian dilanjutkan dengan dekomposisi terhadap kolom data citra. Proses DWT lebih jelasnya dapat ditunjukan pada Gambar 2

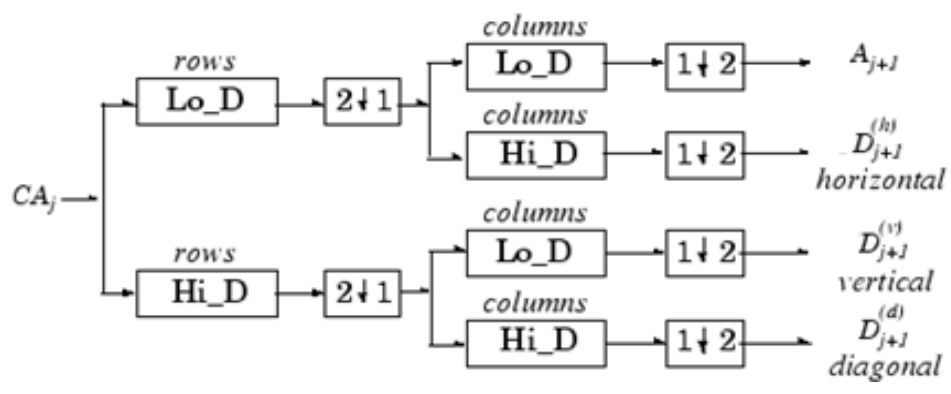

\section{Gambar 2. Discrete Wavelet Transform}

Pada Gambar $2 C A_{j}$, Lo_D dan Hi_D berturut-turut menyatakan signal (citra), lowpass filter dan highpass filter. Operator $2 \downarrow 1$ menyatakan proses downsampling terhadap baris, sedangkan $1 \downarrow$ 2menyatakan proses downsampling terhadap baris.Proses downsampling akan menghasilkan ukuran output $1 / 2$ dari ukuran sinyal semula sehingga pada output terakhir akan dihasilkan $1 / 4$ dari ukuran semula.

Output A disebut komponen aproksimasi, menyatakan bagian koefisien yang diperoleh melalui dua kali proses tapis lowpass. Ketiga komponen outputyang lain $h, v$ dan $d$ disebut komponen detil.Ketiga 
komponen ini melalui proses filterhighpass dalam pembentukannya. Pada makalah ini, proses transformasi wavelet untuk level 1 seperti langkah pada gambar 2 dilakukan terhadap masingmasing matriks citra $\mathrm{R}, \mathrm{G}$, dan B.

Dengan demikian untuk satu citra, dilakukan tiga transformasi, yaitu transformasi terhadap matriks $\mathrm{R}$, matriks G, dan matriks B.Proses transformasi untuk level 2, dilakukan pada citra aproksimasi dari hasil transformasi level 1 dengan mengulang proses transformasi seperti pada level 1. Tahapan proses kompresi citra RGB menggunakan transformasi wavelet dapat dilihat pada Gambar 3 berikut.

Untuk melakukan Inverse Discrete Wavelet Transform IDWT caranya serupa dengan DWT hanya saja prosesnya dibalik. Pada tahap ini diakukan rekonstruksi dengan arah berlawanan dari proses sebelumnya, yaitu dengan upsampling dari pemfilteran dengan koefisien filter balik. Proses ini bertujuan mengembalikan dan menggabungkan sinyal seperti semula.

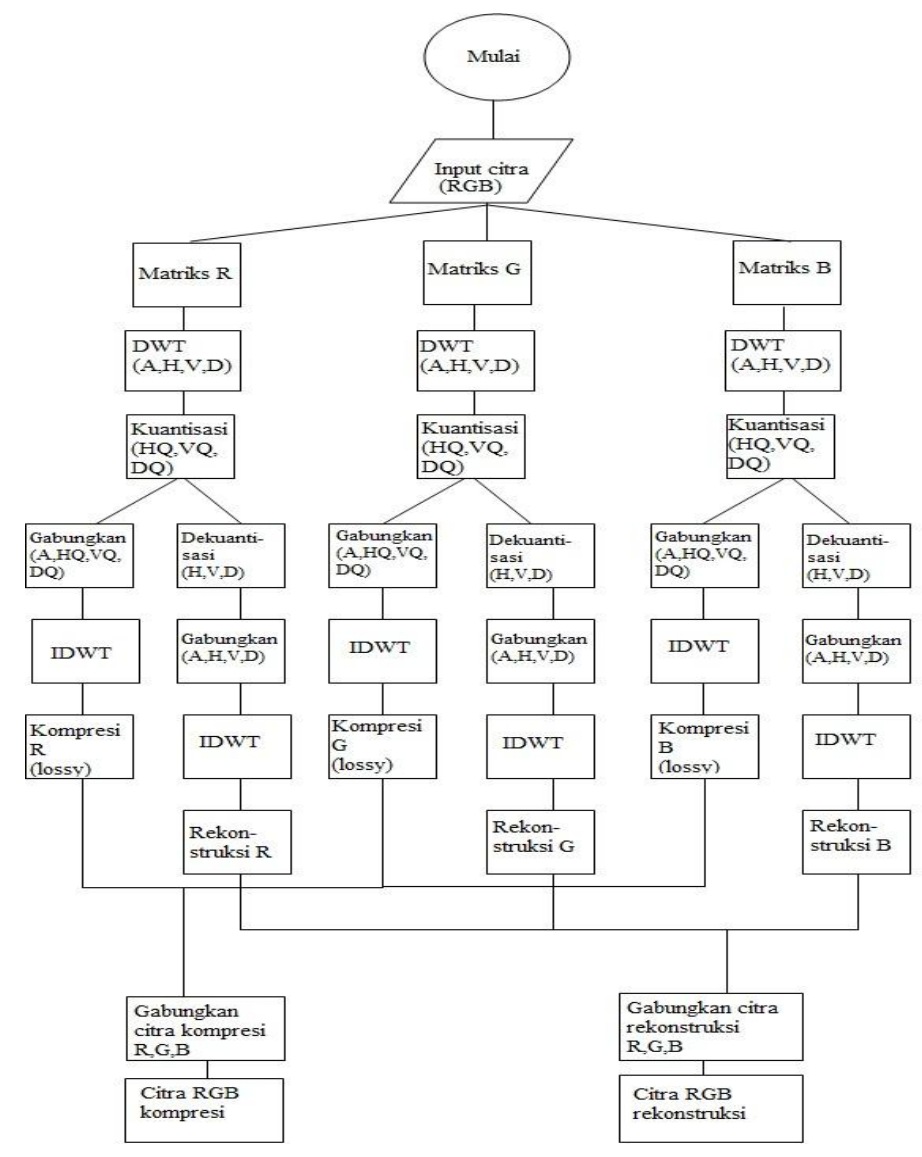

Gambar 3 Tahapan kompresi citramenggunakan metodeDWT

\subsection{Rasio dan KualitasKompresi Citra}

Rasio kompresi citra adalah ukuran persentase citra yang telah berhasil dimampatkan. Secara matematis, rasio pemampatan citra dituliskan sebagai berikut [10]:

$$
\text { Rasio }=100 \%-\left[\frac{\hat{a}}{a} \times 100 \%\right](6)
$$

dengan $\hat{a}=$ hasil kompresi (Bytes) dan $a=$ citra asli (Bytes)'

Kualitas citra hasil kompresi dapat diukur secara kuantitatif dengan pendekatan matematika. Berikut metode yang dapat digunakan untuk mengukur kualitas citra hasil kompresi [10].

\section{Root Mean Square Error (RMSE)}

$$
R M S E=\sqrt{\frac{1}{M \times N} \sum_{x=1}^{M} \sum_{y=1}^{N}(\hat{f}(x, y)-f(x, y))^{2}}
$$




\section{Peak Signal to Noise Ratio (PSNR)}

3. Mean Absolute Percentage Error (MAPE)

$$
P S N R=20 \times \log _{10}\left(\frac{\operatorname{maks} \hat{f}(x, y)}{R M S E}\right)
$$

$$
M A P E=\frac{1}{M \times N} \sum_{x=1}^{M} \sum_{y=1}^{N}\left|\frac{\hat{f}(x, y)-f(x, y)}{f(x, y)}\right|
$$

Dalam hal ini $\hat{f}(x, y)$ dan $f(x, y)$ berturut-turut merupakan fungsi dari citra hasil kompresi dan fungsi dari citra asli dan $M \times N$ adalah ukuran piksel citra, sedangkan maks adalah nilai intensitas terbesar.

\section{Hasil dan Pembahasan}

\subsection{Kompresi Citra Menggunakan Transformasi Wavelet}

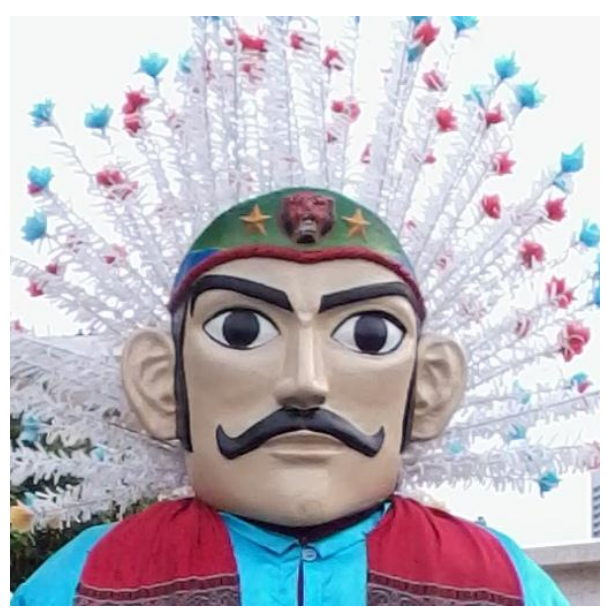

Gambar 4. Citra Input

Citra yang digunakan dalam penelitian ini adalah sebuah citra yang diambil dari kamera handphone dengan resolusi 2.0 MP. Citra tersebut berdimensi 512 x 512 piksel dengan ukuran file sebesar 122.770 Bytes dan dalam format jpg. Citra yang digunakan terdiri dari berbagai variasi warna dimana terdapat tiga warna primer yang cukup dominan dalam citra. Berikut adalah citra yang dimaksud.

Sebelum memasuki tahapan kompresi dan dekompresi citra, citra input yang berjenis true color dipisahkan menjadi tiga buah citra yaitu citra Red, Green dan Blue. Masing-masing citra tersebut setelah dipisahkan memiliki tingkat keabuan 8 bit (grayscale). Proses DWT pertama dilakukan pada citra awal, DWT kedua dilakukan pada komponen aproksimasi hasil DWT pertama. Kemudian semua detil pada komponen citra transformasi dikuantisasi. Selanjutnya citra transformasi dari proses sebelumnya dilakukan dua kali proses IDWT sehingga terbentuklah citra Red, Green dan Blue terkompresi. Lebih jelasnya mengenai tahapan kompresi 2 level dapat dilihat pada Gambar 5.

Tahapan akhir kompresi citra level 2 adalah menggambungkan 3 komponen matriks Red, Green dan Blue yang telah terkompresi. Hasil penggabungan dapat dilihat pada Gambar 6 (a) dan (b)

\subsection{Analisis Kompresi Citra}

Untuk menganalisis hasil kuantitas dan kualitas kompresi adalah dengan memeriksa Root Mean Square Error (RMSE) dan Peak Signal to Noise Ratio (PNSR) dan rasio kompresi dengan menggunakan rumus 6, 7, dan 8. Semakin kecil RMSE, maka kualitas kompresi semakin bagus, artinya bahwa kualitas kompresi citra semakin mendekati citra asli.

Semakin kecil nilai PNSR, maka kuantitas kompresi citra semakin bagus, artinya bahwa ukuran citra terkompresi akan semakin kecil. Nilai PNSR yang baik adalah berada pada rentang $30-50 \mathrm{~dB}$. 
Informasi-informasi pada citra kompresi dirangkum pada Tabel 1 untuk menghitung ketiga aspek tersebut.

Tabel 1 Kesimpulan Kompresi Citra

\begin{tabular}{|l|l|l|l|l|l|}
\hline & Ukuran & Level 1 & Level 2 \\
\cline { 2 - 6 } & Asli & Haar & Db2 & Haar & Db2 \\
\hline Size (Bytes) & 122770 & 45323 & 46045 & 4422 & 41612 \\
\hline Rasio Kompresi (\%) & & 63.08 & 62.49 & 63.98 & 66.11 \\
\hline RMSE & & 5.58080 & 2.7053 & 8.0376 & 5.6499 \\
\hline PSNR (dB) & & 33.1969 & 39.7803 & 30.0261 & 33.6458 \\
\hline MAPE (\%) & & 3.2751 & 1.7169 & 5.2128 & 3.9166 \\
\hline
\end{tabular}

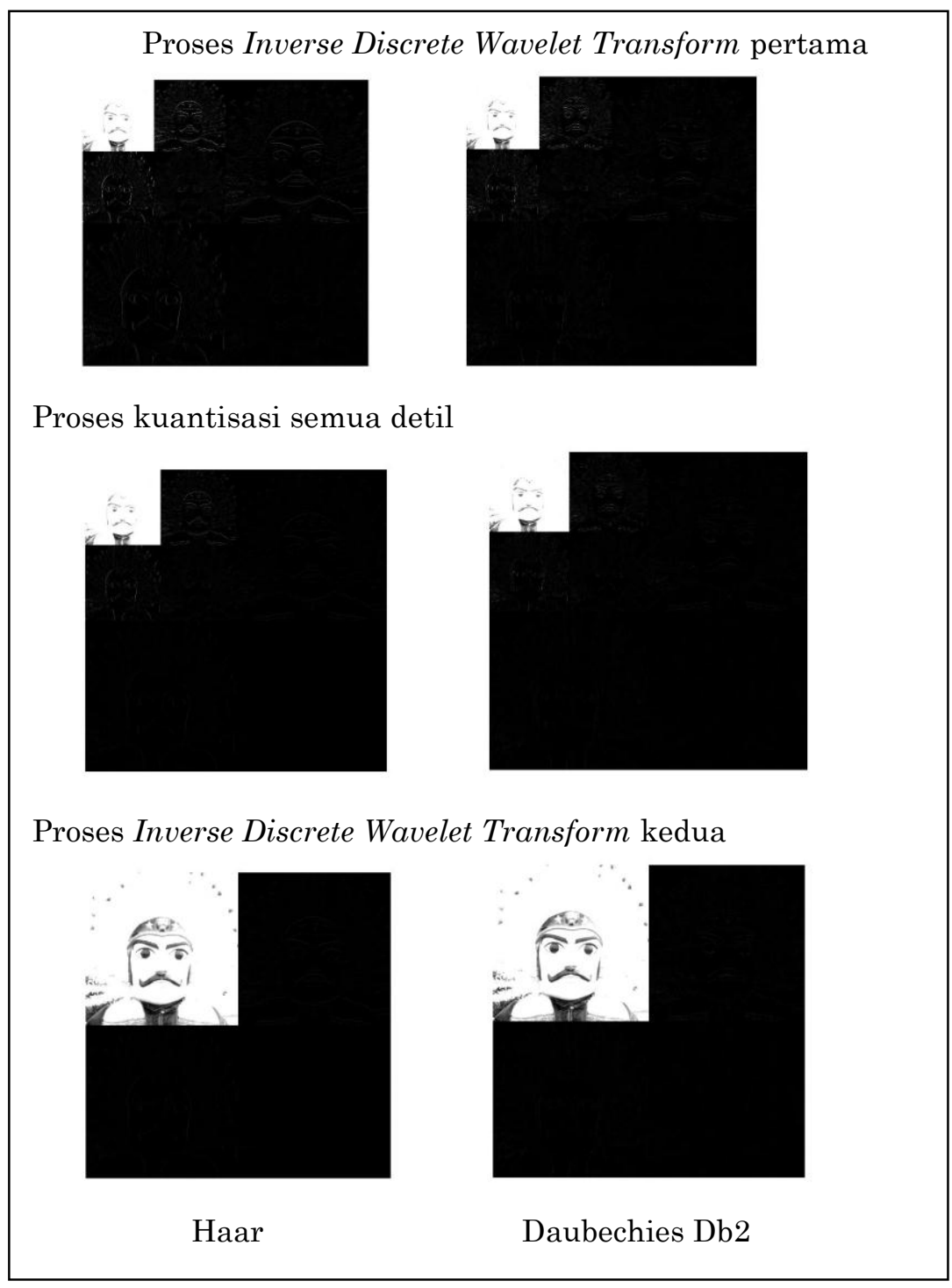

Gambar 5. Kompresi citra 2 Level 


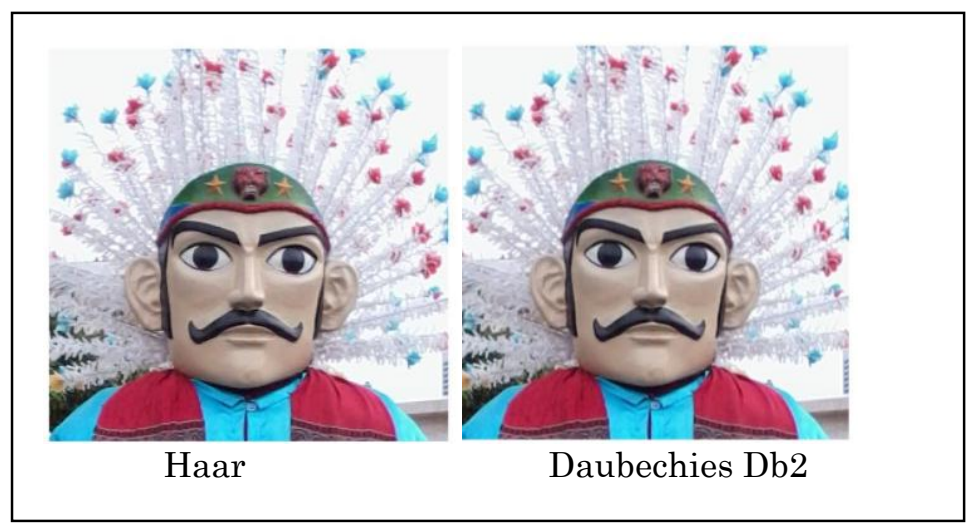

Gambar 6a. Citra Kompresi Level 1

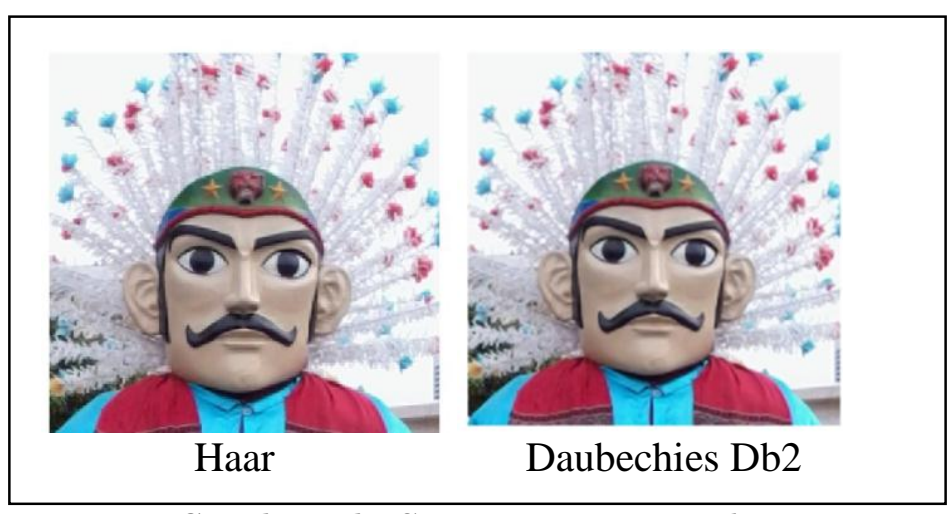

Gambar 6b. Citra Kompresi Level 1

\section{Simpulan}

Berdasarkan Tabel 1 dapat disimpulkan bahwa kualitas kompresi citra, baik dengan 1 level ataupun 2 level transformasi, dengan menggunakan transfromasi wavelet Db2 lebih baik daripada menggunakan transformasi wavelet Haar. Hal dapat dilihat bahwa nilai RMSE pada Db2 lebih kecil dari nilai RMSE pada Haar.

Untuk kuantitas kompresi citra, baik dengan 1 level ataupun 2 level transformasi, dengan menggunakan transformasi wavelet Haar lebih baik daripada menggunakan transformasi wavelet Db2. Hal ini dapat dilihat bahwa nilai PNSR pada Haar lebih kecil daripada nila PNSR pada Db2 dan rasio kompresi pada Db2 adalah 62\% lebih kecil dari pada Haar yang 63\%. Rasio kompresi 62\% artinya citra asli telah berkurang kapasitasnya sebesar 63\%, dan 62\% pada Db2. Secara keseluruhan dapat disimpulkan Db2 level 2 memberikan kompresi yang optimum berdasarkan RMSE, PNSR dan rasio kompresi.

\section{Daftar Pustaka}

1. Dahmen, Wolfgang CS., 1997, Multiscale Wavelet Method for Partial Differensial Equations, Academic Pres.

2. $\quad$ Ferdinand Simanjuntak, 2009., Pengolahan Citra Digital, digilib.ittelkom.ac.id

3. $\quad$ Gonzalez RC et al., 2004., Digital Image Processing Using Matlab. New Jersey: Pearson Prentice,

4. Hernandez, E. \& Weis, G. A., 1996., First Course on Wavelets, CRC Press, New York.

5. Lokenath Debnath, 2002., Wavelet Transform \& Their Applications, Birkhauser Boston Basel Berlin. 
6. Stephane Mallat, 1998., A Wavelet Tour of Signal Processing, Courant Institute New York University.

7. Suma'inna, 2013., Detection of Cardiac Abnormalities Based on ECG Pattern Recognition Using Wavelet and Artificial Neural Network, Far East Journal of Mathematical Sciences (FJMS) 76(1), pp $211-222$.

8. Suma'inna, dan Dedi Lendra, 2013., Aplikasi Wavelet Haar dan Daubechies pada Penentuan Periodisitas Gempa Bumi, UIN Syarif Hidayatullah Jakarta.

9. Suma'inna dan Gugun Gumilar, 2013., Implementasi Transformasi Wavelet Haar dan Debauchies DB2 Dalam Kompresi Citra Digital Cauchy Vol 2 No. 4 Hal. 211 - 215.

10. Sutoyo, T, 2009., Teori Pengolahan Citra Digital, Penerbit Andi, Yogyakarta. 